TITLE:

\title{
Dynamic fearful gaze does not enhance attention orienting in individuals with Asperger's disorder
}

$\operatorname{AUTHOR}(S)$ :

Uono, Shota; Sato, Wataru; Toichi, Motomi

\section{CITATION:}

Uono, Shota ... [et al]. Dynamic fearful gaze does not enhance attention orienting in individuals with Asperger's disorder. Brain and Cognition 2009, 71(3): 229-233

\section{ISSUE DATE:}

2009-12

URL:

http://hdl.handle.net/2433/87428

\section{RIGHT:}

c 2009 Elsevier Inc. All rights reserved.; This is not the published version. Please cite only the published version.; この論文は出版社版でありませ ん。引用の際には出版社版をご確認ご利用ください。 
doi:10.1016/j.bandc.2009.08.015

\section{Dynamic fearful gaze does not enhance attention orienting in individuals with}

\section{Asperger's disorder}

Shota Uono ${ }^{1}$, Wataru $\mathrm{Sato}^{2}$, and Motomi Toichi ${ }^{3}$

${ }^{1}$ Department of Cognitive Psychology in Education, Faculty of Education, Kyoto University, Kyoto, Japan

${ }^{2}$ Department of Comparative Study of Cognitive Development (Funded by Benesse Corporation), Primate Research Institute, Kyoto University, Inuyama, Japan

${ }^{3}$ Faculty of Human Health Science, Graduate School of Medicine, Kyoto University, Kyoto, Japan

Running Head: Gaze-triggered attention in PDD 


\begin{abstract}
Although impaired joint attention is one of the core clinical features of pervasive developmental disorder including autistic disorder and Asperger's disorder, experimental studies failed to report its impairment. This discrepancy might be the result of differences between real-life and experimental situations. The present study examined joint attention in 11 individuals with Asperger's disorder and 11 age-matched controls under naturalistic conditions using a target detection paradigm with dynamic emotional gaze cues. Although both groups showed gaze-triggered attention orienting as assessed by the differences in reaction time for invalid minus valid cues, enhancement of joint attention by fearful (vs. neutral) gaze was observed in the control, but not in the Asperger group. This suggests that the integration of emotion and gaze direction that elicits strong joint attention is impaired in individuals with Asperger's disorder.
\end{abstract}

Keywords:Autism spectrum disorders; Asperger's disorder; Joint attention; Emotion; Gaze; Pervasive developmental disorders

Correspondence: shota-uono@p06.mbox.media.kyoto-u.ac.jp 
Brain and Cognition 71 (2009) 229-233

\section{Introduction}

Pervasive developmental disorder (PDD), including autistic disorder and Asperger's disorder, is characterized by qualitative impairments of social interaction (American Psychiatric Association [APA], 2000). One of the earliest features of these social impairments is a deficit of joint attention (Mundy, Sigman, Ungerer, \& Sherman, 1986). For example, in our previous study, when the attending physician suddenly averted his or her gaze to look at environmental objects during clinical interviews, the individual with PDD did not follow the gaze direction (Okada, Sato, Murai, Kubota, \& Toichi, 2003).

In contrast to such clinical evidence for impaired joint attention, most experimental studies have found intact reflexive joint attention in PDD (Chawarska, Klin, \& Volkmar, 2003; Kylliäinen \& Hietanen, 2004; Okada et al., 2003; Rutherford \& Krysko, 2008; Senju, Tojo, Dairoku, \& Hasegawa, 2004; Swettenham, Condie, Campbell, Milne, \& Coleman, 2003; Vlamings, Stauder, van Son, \& Mottron, 2005; for a review see Nation and Penny (2008)), although there have been reports of impairment (Goldberg et al., 2008; Ristic et al., 2005). These studies applied Posner's (1980) cueing paradigm. For example, Okada et al. presented a face with left- or right-directed eyes to subjects with autism and typically developing controls, with targets appearing on the right or left side of the face. The participants were instructed that the gaze direction did not predict where the target would appear. Nonetheless, the reaction time (RT) to detect a target was shorter for a gazecued (i.e., valid) location than for a gaze-uncued (i.e., invalid) location in both PDD and control groups. These results suggest that reflexive joint attention is intact in individuals with PDD.

Some researchers have pointed out the importance of an emotional component in joint attention (e.g., Mundy \& Sigman, 1989). Others' emotional gaze could be important for evaluating environmental stimuli (Bayliss, Frischen, Fenske, \& Tipper, 2007) and understanding the other's mental state (Shamay-Tsoory, Tibi-Elhanany, \& Aharon-Peretz, 2007). Consistent with this view, recent experimental studies in normally developing individuals found that gaze-triggered attention 
Brain and Cognition 71 (2009) 229-233

orienting was facilitated by emotional facial expressions (Putman, Hermans, \& van Honk, 2006; Tipples, 2006; Uono, Sato, \& Toichi, in press). For example, Uono et al. presented a dynamic emotional or neutral facial cue with left- or right-directed eyes. Participants were asked to detect a target letter. They found that a dynamic fearful gaze cue enhanced the RT difference between valid and invalid conditions compared with a dynamic neutral gaze cue.

Little is known about the effect of emotional facial expressions on reflexive joint attention in individuals with PDD. However, some evidence suggests that the ability to process emotional gaze is impaired. For example, previous studies have reported that individuals with PDD were less likely to combine their gaze signals with emotional facial expressions in social interactions (Dawson, Hill, Spencer, Galpert, \& Watson, 1990; Kasari, Sigman, Mundy, \& Yirmiya, 1990). Moreover, individuals with PDD have been shown to have difficulty in understanding others' mental state from their emotional gaze (Baron-Cohen, Jolliffe, Mortimore, \& Robertson, 1997; Baron-Cohen, Wheelwright, Hill, Raste, \& Plumb, 2001; Baron-Cohen, Wheelwright, \& Jolliffe, 1997). Other studies have reported that individuals with PDD show impaired recognition of facial expressions of emotion, specifically fear (Corden, Chilvers, \& Skuse, 2008; Howard et al., 2000; Humphreys, Minshew, Leonard, \& Behrmann, 2007; Pelphrey et al., 2002), although some other studies have reported intact emotion recognition among people with PDD (Adolphs, Sears, \& Piven, 2001; Castelli, 2005; Grossman, Klin, Carter, \& Volkmar, 2000). Neuroscience studies have revealed an atypical brain response to emotional facial expressions in individuals with PDD (Critchley et al., 2000; Ogai et al., 2003), particularly to fearful faces (Ashwin, Baron-Cohen, Wheelwright, O'Riordan, \& Bullmore, 2007; Dawson, Webb, Carver, Panagiotides, \& McPartland, 2004). These data suggest that individuals with PDD may show atypical patterns of joint attention when gaze is presented in combination with emotional, particularly fearful, facial expressions.

The present study tested reflexive gaze-triggered attention orienting in individuals with Asperger's disorder and an age-matched control group. We used dynamic fearful and neutral gaze 
as cues. The participants were asked to detect a peripheral target following the gaze cue. Based on previous findings, we predicted that the cueing effect (i.e., the RT differences between invalid and valid cues) for a fearful gaze would be greater than that for a neutral gaze in the control group, but not in the Asperger group. Additionally, we predicted that the cueing effect of the neutral gaze would not differ between groups, but that the cueing effect of the fearful gaze would be greater in the control group than in the Asperger group. Furthermore, we conducted exploratory analyses to test whether the results of reflexive joint attention could be accounted for by impairment in general face recognition or emotion recognition.

\section{Methods}

\section{Participants}

Eleven individuals with PDD and 11 controls participated in this study. The Asperger and control groups were matched for chronological age (Asperger group: $17.5 \pm 6.5$ years, range 9-30; control: $19.5 \pm 2.2$ years, range $18-26$; independent t-test, $t(20)=0.88, p>0.1)$ and gender $(8$ males and 3 females in both groups). The Verbal and Performance IQ in the Asperger group was measured using the Japanese version of the Wechsler Adult Intelligence Scale - revised (Shinagawa, Kobayashi, Fujita, \& Maekawa, 1990) or the Wechsler Intelligence Scale for Children - revised (Kodama, Shinagawa, \& Motegi, 1982). The IQs of all of participants in the Asperger group were in the normal range (Full-scale IQ: $M=107.73, S D=9.05$; Verbal IQ: $M=107.55, S D$ $=13.06$; Performance IQ: $M=104.55, S D=10.43$ ).

The participants in the Asperger group were diagnosed with either Asperger's disorder (8 males, 2 females) or pervasive developmental disorder not otherwise specified (PDD-NOS; 1 female) by a child psychiatrist using DSM-IV-TR (APA, 2000). According to DSM-IV-TR, PDD subtypes with a varying degree of severity are classified as PDD-NOS. In this study, one participant diagnosed as 
Brain and Cognition 71 (2009) 229-233

PDD-NOS had milder pathologies than those that occur in Asperger's disorder. The diagnosis was based on an interview with the subjects, information from their parents, teachers, or professional counselors, and clinical records during childhood. The participants in the Asperger group were outpatients who were referred to Kyoto University Hospital or the Faculty of Human Health Science of Kyoto University Graduate School of Medicine for consultation. They were all free of neurological or psychiatric problems other than those associated with PDD, and they were taking no medication. All subjects older than 18 years of age and the parents of those younger than 18 years of age gave written informed consent to participate in this study, which was conducted in accordance with the institutional ethical provisions.

The neuropsychological mechanisms of face recognition and emotion recognition were investigated in all participants using the shortened version of the Benton facial recognition test (Benton, Sivan, Hamsher, Varney, \& Spreen, 1994) and the emotion recognition test using six basic emotional facial expressions (Sato et al., 2002). The data are summarized in Table 1. Although one participant had impaired face recognition, no significant difference in face recognition was found between groups $(t(20)=0.86, p>0.1)$. The results suggested a tendency for individuals with PDD to be better able to recognize surprised faces than control subjects were $(t(20)=2.19, p=0.053)$, but no significant differences between groups were found for the other emotions $(t s(20)<0.90, p s>$ 0.1). In summary, no significant impairments in either face or emotion recognition were found in the PDD group.

\section{Design}

The experiment was constructed as a two-factorial mixed randomized-repeated design, with group (Asperger or control) as the randomized factor, and emotion condition (fearful or neutral) as the repeated factor. 


\section{Stimuli}

We selected the cue stimuli from Ekman and Friesen (1976). Photographs of two models (1 male and 1 female) with neutral and fearful faces were selected and manipulated. The dynamic fearful expressions were created by morphing four intermediate images between the neutral $(0 \%)$ and the fearful (100\%) expressions in $20 \%$ steps using computer-morphing techniques (Mukaida et al., 2000) on a Windows computer.

The gaze direction was then manipulated. The irises and pupils of the eyes were cut from the original photographs and pasted to fit on the right or left side of the eyes using Photoshop 5.0 (Adobe). The irises and pupils for the intermediate photographs were fit to the position matching each transformation percentage. We cropped the photographs in an ellipse $4.6^{\circ}$ wide and $6.2^{\circ}$ high to exclude the hair and background.

We presented the stimuli sequentially from $0 \%$ (neutral) to $100 \%$ (original fearful) under the fearful gaze condition. The first $0 \%$ image was presented for $300 \mathrm{~ms}$, and each intermediate image were presented for $20 \mathrm{~ms}$. The last $100 \%$ image remained until a response was made. Under the neutral gaze conditions, only the gaze direction was changed dynamically. A total of 42 photographs were used as dynamic gaze cue stimuli: emotion (neutral and fearful) gaze direction (four intermediate positions for right and left and an end position for right and left) person (two models), and a neutral face with straight gaze for two models. An example of the dynamic emotional expression cue is shown in Fig. 1 . The target stimulus was a letter $\mathrm{T}\left(1^{\circ}\right.$ wide and $1^{\circ}$ high $)$ presented $9.0^{\circ}$ to the left or right side of the center of the screen.

\section{Apparatus}

Stimulus presentation and data acquisition were controlled by Presentation ${ }^{\circledR}$ (Neurobehavioral Systems) on a Windows computer (HP xw4300 Workstation). Stimuli were presented on a 17-inch CRT monitor (Iiyama; screen resolution $1024 \times 768$ pixels; refresh rate $100 \mathrm{~Hz}$ ). The distance between the monitor and the participants was fixed at approximately $57 \mathrm{~cm}$ using a headrest. 


\section{Procedure}

The sequence of stimulus presentation is shown Fig. 1. In each trial, a fixation cross was first presented at the center of the screen for $600 \mathrm{~ms}$. Subsequently, a dynamic emotional or neutral facial cue with the eyes gazing sideways (right or left) was presented at the center of the screen. After $80 \mathrm{~ms}$, the target letter T appeared to the left or right side of the cue stimulus. The participants were asked to press a button as quickly as possible when a target appeared. The interval from target appearance to button response was measured in each trial. The target and cue remained on the screen until a response was made. If $1500 \mathrm{~ms}$ elapsed with no response, the next trial was started. The participants were told that the cues did not predict the target location and were instructed to fixate on the center of the screen in each trial.

The experiment consisted of eight blocks of 28 trials, including 32 catch trials in which the target did not appear. Forty-eight trials were performed under each condition. The trials were presented in pseudorandom order such that the same condition appeared once in four consecutive trials. Participants were allowed to rest between blocks. Thirty practice trials preceded the experimental trials.

\section{Data analysis}

The data were analyzed using SPSS 10.0 J (SPSS Japan). Incorrect responses and responses of less than $100 \mathrm{~ms}$ were excluded from the RT analysis. The median RT under each condition was calculated for each participant. The RT differences between the invalid and the valid cues under facial expression conditions were calculated as a measure of the shift of attention, or the gazecueing effect, as described in previous studies (e.g., Okada, Sato, \& Toichi, 2006). First, to test the cueing effect, the RT difference under each condition was tested for the difference from zero using one-sample t-tests. Then, the RT differences were analyzed in a two-way analysis of variance (ANOVA) with emotion (fearful and neutral) as the within-participant factor and group (Asperger 
Brain and Cognition 71 (2009) 229-233

and control) as the between-participant factor. For significant interactions, if present, follow-up simple-effect analyses were conducted. Non-parametric Mann-Whitney U-tests were conducted to confirm the results. We further conducted an analysis of covariance (ANCOVA) using the Benton facial recognition test scores and correct scores of fearful facial expressions as covariates. A preliminary ANCOVA using participant's age as a covariate showed that the age did not affect the group emotion interaction; therefore, age was omitted in the subsequent analyses. Preliminary analyses also showed that the error rates in catch trials were small in both groups $(<8 \%)$, and no evidence of a speed-accuracy trade-off was observed; thus, we report only the RT results.

\section{Results}

The mean (with SE) median RTs for each condition are shown in Table 2. The mean (with SE) RT differences between the invalid and the valid conditions are shown in Fig. 2. One-sample t-tests indicated that the cueing effects were significantly larger than zero under both emotion conditions in both groups (all $p<0.05)$.

The ANOVA revealed a significant main effect of emotion, $F(1,20)=6.54, p<0.05$, and interaction of emotion group, $F(1,20)=5.16, p<0.05$. Simple main effect analyses revealed that the cueing effect for fearful gaze was significantly larger than that for neutral gaze in the control group, $F(1,20)=11.67, p<0.01$, but not in the Asperger group $(p>0.1)$. A further simple main effect analysis revealed that the cueing effects for fearful and neutral gaze were not significantly different between groups $(p>0.1)$. A Mann-Whitney U-test revealed that the difference between groups was marginally significant for fearful gaze $(U=32.0, p=0.06)$ but not significant for neutral gaze $(U=48.0, p>0.1)$.

The ANCOVA using face recognition and recognition of fearful expression as covariates showed that the interaction of emotion group remained significant $(F(1,18)=5.89, p<0.05)$. The 
results suggest that face recognition and recognition of fearful expression cannot account for differences in the effect of fearful gaze on attention orienting.

\section{Discussion}

Two major findings emerged from the present study. First, a significant difference in RT was found for invalid vs. valid cues, regardless of the emotion expressed by the gaze, in both the control and Asperger groups. A debate exists about the ability of individuals with PDD to orient their attention, specifically that triggered by non-social cues (e.g., Iarocci \& Burack, 2004; Renner, Klinger, \& Klinger, 2006). However, our results, together with those of several previous studies (e.g., Okada et al., 2003; see Nation and Penny (2008) for a review), clearly indicate that gazetriggered orienting is not impaired in individuals with PDD.

Second, and more importantly, the RT difference for the fearful gaze was greater than that for the neutral gaze in the control group, but not in the Asperger group. The finding that a fearful gaze facilitates reflexive attention orienting in the control group is consistent with the results of previous studies (Putman et al., 2006; Tipples, 2006; Uono et al., in press). Impaired integration of emotional expression and gaze direction in the Asperger group is in line with previous studies investigating social cognition (Baron-Cohen, Jolliffe, et al., 1997; Baron-Cohen et al., 2001; Baron-Cohen, Wheelwright, et al., 1997). Further, the finding of inefficient processing of a fearful gaze in the Asperger group confirms previous behavioral (Corden et al., 2008; Howard et al., 2000; Humphreys et al. 2007; Pelphrey et al., 2002) and neuroscience (Ashwin et al., 2007; Dawson et al., 2004) reports. The result of the present study extend the data on joint attention and expression processing and, to our knowledge, provides the first evidence that a fearful gaze does not facilitate reflexive attention orienting in individuals with Asperger's disorder. 
Brain and Cognition 71 (2009) 229-233

Further, our results indicate that deficits in face recognition and emotion recognition do not account for this impairment. The finding that these abilities are normal in individuals with PDD is consistent with studies of emotional processing in PDD (Adolphs et al., 2001; Castelli, 2005; Grossman et al., 2000). However, some studies have reported impaired perception of facial configurations (see Behrmann, Thomas, and Humphreys (2006) for a review) or enhanced perception of facial features (see Behrmann et al. (2006) and Mottron, Dawson, Soulieres, Hubert, and Burack (2006) for reviews) in PDD. Other studies report impaired recognition of facial expressions of emotion, specifically fear, in individuals with PDD (Corden et al., 2008; Howard et al., 2000; Humphreys et al., 2007; Pelphrey et al., 2002). Our sample size was small, and the possibility of impaired face recognition and emotion recognition in PDD cannot be completely ruled out. Nevertheless, our findings clearly indicate that the facilitative effect of fearful gaze on reflexive attention orienting was impaired in the Asperger group, despite no clear impairment in the face or emotion recognition. Previous studies reported that individuals with PDD were less likely to combine their gaze signals with emotional facial expressions in social interactions, although they used these signals individually as often as did people without PDD (Dawson et al., 1990; Kasari et al., 1990). Our findings, together with these previous data, suggest that individuals with PDD have difficulty in integrating emotional expressions and gaze direction rather than in processing the individual social signals.

Our results partly explain the difference between clinical observations and experimental results in joint attention behavior in individuals with PDD. In real-life communication, others' emotional gaze plays an important role in evaluating attended objects (Bayliss et al., 2007) and in understanding others' mental states (Shamay-Tsoory et al., 2007). Mundy and Sigman (1989) proposed that sharing emotion in joint attention induces the development of socio-emotional functions. Given that the impairment of joint attention in PDD predicts later deficits in language 
Brain and Cognition 71 (2009) 229-233

skills and social communications (Charman, 2003), impaired processing of emotional gaze might underlie the deficit in more complex social and cognitive functions.

The amygdala is thought to be involved in the processing of both gaze and emotion. A recent study of patients with unilateralamygdala incision reported amygdala involvement in reflexive joint attention (Okada et al., 2008). Neuroimaging studies in subjects without PDD have indicated that the amygdala is involved in the processing of fearful expressions (Sato, Kochiyama, Yoshikawa, Naito, \& Matsumura, 2004) and that amygdala activity reflects the interaction between emotional expression and gaze direction (Sato, Yoshikawa, Kochiyama, \& Matsumura, 2004). Magnetic resonance imaging (MRI) studies have reported that the amygdala shows an abnormal developmental trajectory in PDD (Nacewicz et al., 2006; Schumann et al., 2004). Neuroimaging studies reveal that the amygdala of individuals with PDD is less active in response to fearful expressions (Ashwin et al., 2007) and emotional gaze (Baron-Cohen et al., 1999) than is that in controls. Taken together, these findings suggest that a dysfunction of the amygdala in PDD that interferes with the integrative processing of gaze direction and emotion may explain the failure to elicit efficient attention orienting to a dynamic fearful gaze.

The RT for the fearful gaze condition was faster than that for the neutral gaze condition in the Asperger group, regardless of cue validity (see Table 1). This finding was confirmed with an emotion validity ANOVA (significant main effects of emotion, $F(1,10)=18.95, p<0.001$ and validity, $F(1,10)=24.13, p<0.001)$. This unexpected finding indicates that, in individuals with Asperger's disorder, processing a fearful gaze might result in overall enhancement of visual processing, not simply selective facilitation of joint attention, reflecting undifferentiated emotional development. Indirect evidence is available to support this interpretation. Neuroimaging studies have shown that the visual cortex is more active in individuals with PDD than in control subjects during face processing (Hubl et al., 2003) and theory of mind tasks (Castelli, Frith, Happe, \& Frith, 2002). Hall, Szechtman, and Nahmias (2003) reported that the primary visual cortex is more active 
Brain and Cognition 71 (2009) 229-233

during an emotion perception task than during a gender discrimination task in individuals with PDD. Further studies are needed to elucidate whether this atypical processing strategy extends to reflexive joint attention.

A limitation of this study is that we tested only fearful gaze. In real-life communication, a happy gaze may facilitate the sharing of intention, which could also be impaired in individuals with PDD. Emotions other than fear should be examined in future research.

In summary, the present study found that dynamic fearful expression enhanced gaze-triggered attention orienting in control subjects, but not in individuals with Asperger's disorder, despite normal face and emotion recognition. These results suggest that the ability to integrate emotional processing and gaze processing is impaired in individuals with PDD, and the amygdala may play an important role in this process. This finding might bridge the gap between normal joint attention reported in experimental studies and impaired joint attention behaviors in real-life. 


\section{References}

Adolphs, R., Sears, L., \& Piven, J. (2001). Abnormal processing of social information from faces in autism. Journal of Cognitive Neuroscience, 13, 232-240.

American Psychiatric Association (2000). Diagnostic and statistical manual for mental disorders (DSM-IV-TR). Washington, DC: APA.

Ashwin, C., Baron-Cohen, S., Wheelwright, S., O’Riordan, M., \& Bullmore, E. (2007). Differential activation of the amygdala and the 'social brain' during fearful faceprocessing in Asperger syndrome. Neuropsychologia, 45, 2-14.

Baron-Cohen, S., Jolliffe, T., Mortimore, C., \& Robertson, M. (1997). Another advanced test of theory of mind: Evidence from very high-functioning adults with autism or Asperger syndrome. Journal of Child Psychology and Psychiatry, 38, 813-822.

Baron-Cohen, S., Ring, H. A., Wheelwright, S., Bullmore, E. T., Brammer, M. J., Simmons, A., et al. (1999). Social intelligence in the normal and autistic brain: An fMRI study. European Journal of Neuroscience, 11, 1891-1898.

Baron-Cohen, S., Wheelwright, S., Hill, J., Raste, Y., \& Plumb, I. (2001). The "Reading the Mind in the Eyes test" revised version: A study with normal adults, and adults with Asperger syndrome or high-functioning autism. Journal of Child Psychology and Psychiatry, 42, 241251.

Baron-Cohen, S., Wheelwright, S., \& Jolliffe, T. (1997). Is there a "language of the eyes"? Evidence from normal adults and adults with autism or Asperger syndrome. Visual Cognition, 4, $311-331$.

Bayliss, A. P., Frischen, A., Fenske, M. J., \& Tipper, S. P. (2007). Affective evaluations of objects are influenced by observed gaze direction and emotional expression. Cognition, 104, 644-653. 
Brain and Cognition 71 (2009) 229-233

Behrmann, M., Thomas, C., \& Humphreys, K. (2006). Seeing it differently: Visual processing in autism. Trends in Cognitive Sciences, 10, 258-264.

Benton, A. L., Sivan, A. B., Hamsher, K., Varney, N. R., \& Spreen, O. (1994). Contributions to neuropsychological assessment. New York: Oxford University Press.

Castelli, F. (2005). Understanding emotions from standardized facial expressions in autism and normal development. Autism, 9, 428-449.

Castelli, F., Frith, C., Happe, F., \& Frith, U. (2002). Autism, Asperger syndrome and brain mechanisms for the attribution of mental states to animated shapes. Brain, 125, 1839-1849.

Charman, T. (2003). Why is joint attention a pivotal skill in autism? Philosophical Transactions of the Royal Society of London B-Biological Science, 358, 315-324.

Chawarska, K., Klin, A., \& Volkmar, F. (2003). Automatic attention cueing through eye movement in 2-year-old children with autism. Child Development, 74, 1108-1122.

Corden, B., Chilvers, R., \& Skuse, D. (2008). Avoidance of emotionally arousing stimuli predicts social-perceptual impairment in Asperger's syndrome. Neuropsychologia, 46, 137-147.

Critchley, H. D., Daly, E. M., Bullmore, E. T., Williams, S. C. R., van Amelsvoort, T., Robertson, D. M., et al. (2000). The functional neuroanatomy of social behaviour: Changes in cerebral blood flow when people with autistic disorder process facial expressions. Brain, 123, 2203-2212.

Dawson, G., Hill, D., Spencer, A., Galpert, L., \& Watson, L. (1990). Affective exchanges between young autistic children and their mothers. Journal of Abnormal Child Psychology, 18, 335-345.

Dawson, G., Webb, S. J., Carver, L., Panagiotides, H., \& McPartland, J. (2004). Young children with autism show atypical brain responses to fearful versus neutral facial expressions of emotion. Developmental Science, 7, 340-359.

Ekman, P., \& Friesen, W. V. (1976). Pictures offacial affect. Palo Alto, CA: Consulting Psychologists Press.

Goldberg, M. C., Mostow, A. J., Vecera, S. P., Larson, J. C. G., Mostofsky, S. H., Mahone, E. M., et 
Brain and Cognition 71 (2009) 229-233

al. (2008). Evidence for impairments in using static line drawings of eye gaze cues to orient visual-spatial attention in children with high functioning autism. Journal of Autism and Developmental Disorders, 38, 1405-1413.

Grossman, J. B., Klin, A., Carter, A. S., \& Volkmar, F. R. (2000). Verbal bias in recognition of facial emotions in children with Asperger syndrome. Journal of Child Psychology and Psychiatry, 41, 369-379.

Hall, G. B., Szechtman, H., \& Nahmias, C. (2003). Enhanced salience and emotion recognition in autism: A PET study. American Journal of Psychiatry, 160, 1439-1441.

Howard, M. A., Cowell, P. E., Boucher, J., Broks, P., Mayes, A., Farrant, A., et al. (2000). Convergent neuroanatomical and behavioural evidence of an amygdala hypothesis of autism. NeuroReport, 11, 2931-2935.

Hubl, D., Bo“lte, S., Feineis-Matthews, S., Lanfermann, H., Federspiel, A., Strik, W., et al. (2003). Functional imbalance of visual pathways indicates alternative face processing strategies in autism. Neurology, 61, 1232-1237.

Humphreys, K., Minshew, N., Leonard, G. L., \& Behrmann, M. (2007). A fine-grained analysis of facial expression processing in high-functioning adults with autism. Neuropsychologia, 45, $685-695$.

Iarocci, G., \& Burack, J. A. (2004). Intact covert orienting to peripheral cues among children with autism. Journal of Autism and Developmental Disorders, 34, 257-264.

Kasari, C., Sigman, M., Mundy, P., \& Yirmiya, N. (1990). Affective sharing in the context of joint attention interactions of normal, autistic, and mentally retarded children. Journal of Autism and Developmental Disorders, 20, 87-100.

Kodama, H., Shinagawa, F., \& Motegi, M. (1982). Japanese Wechsler intelligence scale for children - Revised. Tokyo: Nihon-Bunka-Kagaku-sha.

Kylliäinen, A., \& Hietanen, J. K. (2004). Attention orienting by another's gaze direction in children 
Brain and Cognition 71 (2009) 229-233

with autism. Journal of Child Psychology and Psychiatry, 45, 435-444.

Mottron, L., Dawson, M., Soulieres, I., Hubert, B., \& Burack, J. (2006). Enhanced perceptual functioning in autism: An update, and eight principles of autistic perception. Journal of Autism and Developmental Disorders, 36, 27-43.

Mukaida, S., Kamachi, M., Kato, T., Oda, M., Yoshikawa, S., \& Akamatsu, S. (2000). Foolproof utilities for facial image manipulation. Kyoto: ATR [unpublished computer software].

Mundy, P., \& Sigman, M. (1989). The theoretical implications of joint attention deficits in autism. Development and Psychopathology, 1, 173-183.

Mundy, P., Sigman, M., Ungerer, J., \& Sherman, T. (1986). Defining the social deficits of autism: The contribution of nonverbal communication measures. Journal of Child Psychology and Psychiatry, 27, 657-669.

Nacewicz, B. M., Dalton, K. M., Johnstone, T., Long, M. T., McAuliff, E. M., Oakes, T. R., et al. (2006). Amygdala volume and nonverbal social impairment in adolescent and adult males with autism. Archives of General Psychiatry, 63, 1417-1428.

Nation, K., \& Penny, S. (2008). Sensitivity to eye gaze in autism: Is it normal? Is it automatic? Is it social? Development and Psychopathology, 20, 79-97.

Ogai, M., Matsumoto, H., Suzuki, K., Ozawa, F., Fukuda, R., Uchiyama, I., et al. (2003). fMRI study of recognition of facial expressions in high-functioning autistic patients. NeuroReport, 14, $559-563$.

Okada, T., Sato, W., Kubota, Y., Usui, K., Inoue, Y., Murai, T., et al. (2008). Involvement of medial temporal structures in reflexive attentional shift by gaze. Social Cognitive and Affective Neuroscience, 3, 80-88.

Okada, T., Sato, W., Murai, T., Kubota, Y., \& Toichi, M. (2003). Eye gaze triggers visuospatial attentional shift in individuals with autism. Psychologia, 46, 246-254.

Okada, T., Sato, W., \& Toichi, M. (2006). Right hemispheric dominance in gaze-triggered reflexive 
shift of attention in humans. Brain and Cognition, 62, 128-133.

Pelphrey, K. A., Sasson, N. J., Reznick, J. S., Paul, G., Goldman, B. D., \& Piven, J. (2002).Visual scanning of faces in autism. Journal of Autism and Developmental Disorders, 32, 249-261.

Posner, M. I. (1980). Orienting of attention. Quarterly Journal of Experimental Psychology, 32, 325.

Putman, P., Hermans, E., \& van Honk, J. (2006). Anxiety meets fear in perception of dynamic expressive gaze. Emotion, 6, 94-102.

Renner, P., Klinger, L. G., \& Klinger, M. R. (2006). Exogenous and endogenous attention orienting in autism spectrum disorders. Child Neuropsychology, 12, 361-382.

Ristic, J., Mottron, L., Friesen, C. K., Iarocci, G., Burack, J. A., \& Kingstone, A. (2005). Eyes are special, but not for everyone: The case of autism. Cognitive Brain Research, 24, 715-718.

Rutherford, M. D., \& Krysko, K. M. (2008). Eye direction, not movement direction, predicts attention shifts in those with autism spectrum disorders. Journal of Autism and Developmental Disorders, 38, 1958-1965.

Sato, W., Kochiyama, T., Yoshikawa, S., Naito, E., \& Matsumura, M. (2004). Enhanced neural activity in response to dynamic facial expressions of emotion: An fMRI study. Cognitive Brain Research, 20, 81-91.

Sato, W., Kubota, Y., Okada, T., Murai, T., Yoshikawa, S., \& Sengoku, A. (2002). Seeing happy emotion in fearful and angry faces: Qualitative analysis of the facial expression recognition in a bilateral amygdala-damaged patient. Cortex, 38, 727-742.

Sato, W., Yoshikawa, S., Kochiyama, T., \& Matsumura, M. (2004). The amygdala processes the emotional significance of facial expressions: An fMRI investigation using the interaction between expression and face direction. NeuroImage, 22, 1006-1013.

Schumann, C. M., Hamstra, J., Goodlin-Jones, B. L., Lotspeich, L. J., Kwon, H., Buonocore, M. H., et al. (2004). The amygdala is enlarged in children but not adolescents with autism; 
Brain and Cognition 71 (2009) 229-233

Hippocampus is enlarged at all ages. The Journal of Neuroscience, 24, 6392-6401.

Senju, A., Tojo, Y., Dairoku, H., \& Hasegawa, T. (2004). Reflexive orienting in response to eye gaze and an arrow in children with and without autism. Journal of Child Psychology and Psychiatry, 45, 445-458.

Shamay-Tsoory, S. G., Tibi-Elhanany, Y., \& Aharon-Peretz, J. (2007). The green-eyed monster and malicious joy: The neuroanatomical bases of envy and gloating (schadenfreude). Brain, 130, $1663-1678$.

Shinagawa, F., Kobayashi, S., Fujita, K., \& Maekawa, H. (1990). Japanese Wechsler adult intelligence scale - Revised. Tokyo: Nihon-Bunka-Kagaku-sha.

Swettenham, J., Condie, S., Campbell, R., Milne, E., \& Coleman, M. (2003). Does the perception of moving eyes trigger reflexive visual orienting in autism? Philosophical Transaction of the Royal Society of London B-Biological Science, 358, 325-334.

Tipples, J. (2006). Fear and fearfulness potentiate automatic orienting to eye gaze. Cognition and Emotion, 20, 309-320.

Uono, S., Sato, W., \& Toichi, M. (2010). Dynamic fearful expressions enhance gaze-triggered attention orienting in high and low anxiety individuals. Social Behavior and Personality, 38, 1. (in press)

Vlamings, P. H. J. M., Stauder, J. E. A., van Son, I. A. M., \& Mottron, L. (2005). Atypical visual orienting to gaze- and arrow-cues in adults with high functioning autism. Journal of Autism and Developmental Disorders, 35, 267-277. 
Brain and Cognition 71 (2009) 229-233

\section{Author Note}

Shota Uono: Department of Cognitive Psychology in Education, Faculty of Education, Kyoto University, Yoshida-honmachi, Sakyo-ku, Kyoto 606-8501, Japan. Wataru Sato: Department of Comparative Study of Cognitive Development (Funded by Benesse Corporation), Primate Research Institute, Kyoto University, Inuyama, Aichi 484-8506, Japan. Motomi Toichi: Faculty of Human Health Science, Graduate School of Medicine, Kyoto University, Shogoin Kawahara-cho, Sakyo-ku, Kyoto 606-8507, Japan.

Correspondence concerning this article should be addressed to Shota Uono (Department of Cognitive Psychology in Education, Faculty of Education, Kyoto University, Sakyo-ku, Kyoto, 606-8501, Japan. Tel: +81-75-753-3067; Fax: +81-75-753-3067; E-mail: shotauono@p06.mbox.media.kyoto-u.ac.jp). 


\section{Table 1.}

Mean (with SE) scores of Benton facial recognition test (out of 27) and mean (with SE) percentages of accurate emotion recognition.

\begin{tabular}{lccccccc}
\hline & $\begin{array}{c}\text { Benton } \\
\text { (out of 27) }\end{array}$ & \multicolumn{5}{c}{$\begin{array}{c}\text { Emotion Recognition } \\
\text { (\%) }\end{array}$} \\
\cline { 3 - 8 } & & Anger & Disgust & Fear & Happy & Sad & Surprise \\
\hline \multirow{2}{*}{ Control } & $23.5(0.7)$ & $59.1(5.9)$ & $40.9(6.5)$ & $44.3(7.4)$ & $97.7(1.5)$ & $80.7(5.4)$ & $94.3(2.6)$ \\
Asperger & $22.4(0.9)$ & $61.4(5.9)$ & $45.5(6.1)$ & $34.1(8.9)$ & $96.6(1.8)$ & $87.5(5.3)$ & $100(0)$ \\
\hline
\end{tabular}

\section{Table 2.}

The mean (with $S E$ ) median RTs for each condition in control and Asperger group

\begin{tabular}{cccccc}
\hline & \multicolumn{2}{c}{ Control } & & \multicolumn{2}{c}{ Asperger } \\
\cline { 2 - 3 } \cline { 5 - 6 } Facial expression & Valid & Invalid & & Valid & Invalid \\
\hline Fearful & $281.3(7.6)$ & $306.4(6.1)$ & & $291(12.1)$ & $308.3(14.4)$ \\
Neutral & $291.3(5.4)$ & $301.8(5.3)$ & & $306.3(13.3)$ & $322.8(16.5)$ \\
\hline
\end{tabular}


Brain and Cognition 71 (2009) 229-233

\section{Figure Captions}

Figure 1. The stimulus presentation sequence under the fearful and invalid gaze conditions.

Figure 2. Mean (with $S E$ ) RT differences between invalid and valid gaze conditions for the Asperger and control groups. The error bars represent standard errors. 


\section{Figure 1.}

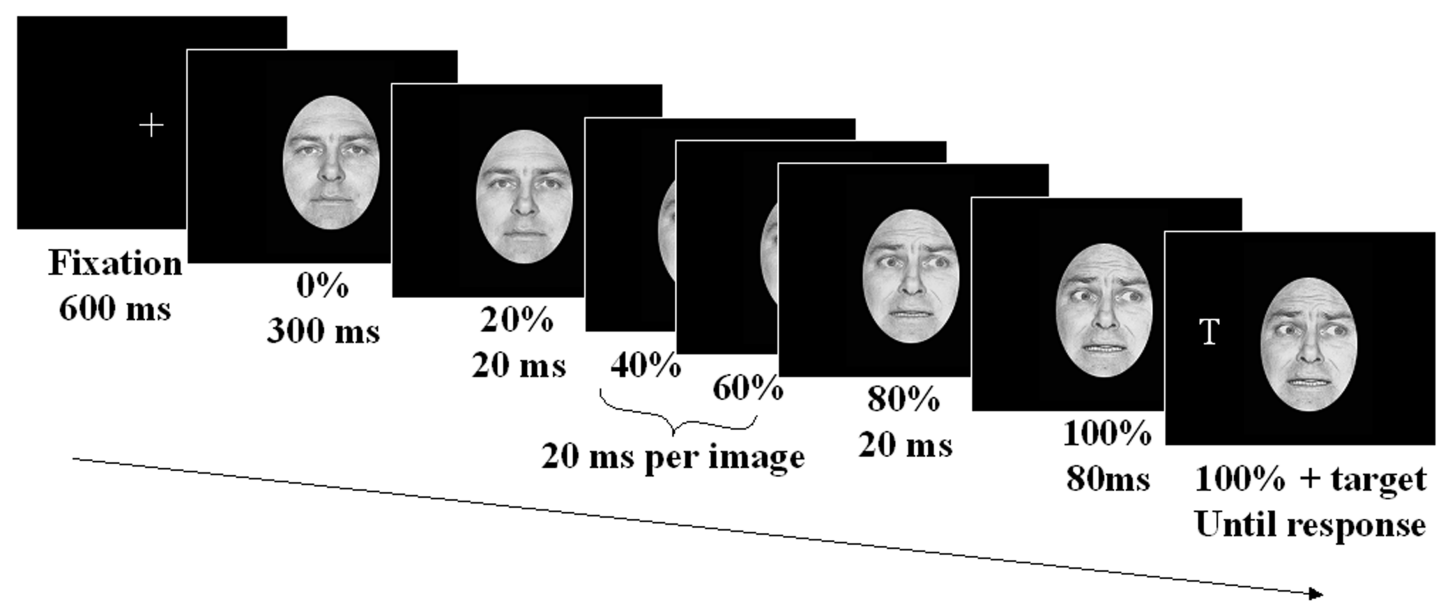


Figure 2.

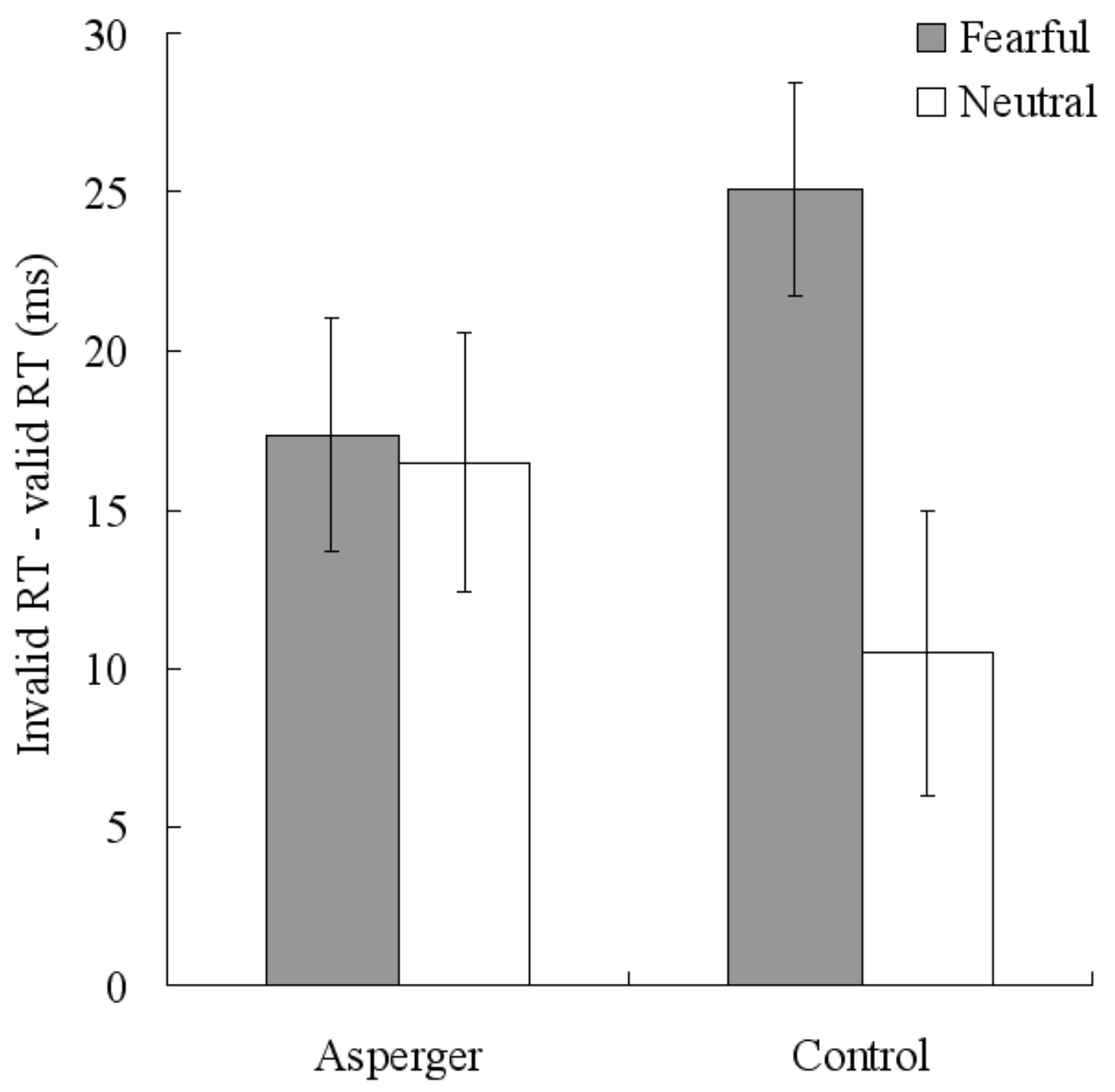

